\title{
Research Note \\ Manoeuvring the Complexities of Field Research in Africa: Experiences from Voter Turnout Research in Ghana
}

\author{
Fortune Agbele ${ }^{1}$ (D) and Alexander Stroh' ${ }^{1}$ (D) \\ ${ }^{1}$ Bayreuth International Graduate School of African Studies (BIGSAS), University of Bayreuth, Bayreuth Germany.
}

\begin{abstract}
Field research enables interaction between a researcher and research participants, offering an opportunity for the discovery of primary empirical data. As exciting as field research can be, for a novice researcher or research in unfamiliar terrain, community field research can also be daunting. These challenges may include, but are not limited to, the determination of community entry strategies, identification of potential respondents, as well as dealing with the non-availability of respondents. Based on field experiences, this research note offers practical suggestions on how to deal with these challenges within the realm of political science fieldwork. The experiences from a Voter Turnout research in Ghana shared in this note are of particular relevance to field research designs in the subject area of voter participation, focusing on voters as informants rather than experts or members of a professional network.
\end{abstract}

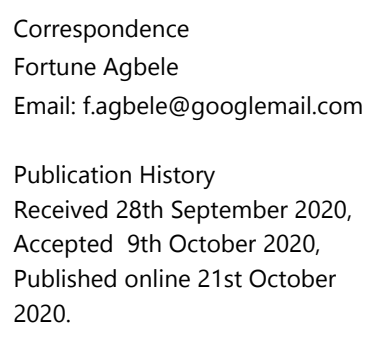

Correspondence

Fortune Agbele

Email: f.agbele@googlemail.com

Publication History

ved 28th Septeml

2020.

Keywords: Field Research; Political Science; Field Strategies; Voter Turnout.

\section{INTRODUCTION}

Conducting field research, i.e., whether quantitative or qualitative research in communities ${ }^{1}$ can be an exciting engagement for a primary empirical data generation process. It offers the unique opportunity for researchers to interact, discover and gather at first-hand relevant data, which may not be available as secondary data. As noted by Wood, the interaction between researchers and the subjects facilitates some learnings for the researcher, as well as findings, which could contradict presumptions with which the researcher goes to field. ${ }^{2}$ Experiences from the field thus give life to storytelling as it allows the researcher to immerse him/herself in the field context being studied. That said, this aspect of the research could also be daunted by challenges, ${ }^{3}$ particularly for novice researchers or researchers who are unfamiliar with the research sites. Within such a context, questions like how to identify and contact potential respondents; how to deal with the non-availability of respondents and unwillingness on the part of participants to have interviews recorded; how to deal with the dilemma of the expectations for incentives and or the ethical concerns of giving incentives arise. Based on field experience, this paper provides practical suggestions on how to deal with the above-listed challenges.

Until recently, little has been written on conducting political science field research as much of the specifics of field research are borrowed from other disciplines. ${ }^{4}$ Besides, much of the existing works on methods employed by political scientists in the conduct of research focuses on other methodological elements in neglect of the challenges and complexities entailed in collecting data and how these complexities are manoeuvred during fieldwork. ${ }^{5}$ Little consensus exists on the definition of fieldwork even within the political science discipline. Wood, for instance, defined field research as "research based on personal interaction with research subjects in their own setting." ${ }^{\circ}$ Similarly, Kapiszewski et al., view

\footnotetext{
Communities as used in this note is a geographical unit, which may consist of a town, a city or an area. Miretta Prezza, et. al. 2001. "Sense of Community Referred to the Whole Town: Its Relations with Neighboring, Loneliness, Life Satisfaction, and Area of Residence." Journal of Community Psychology 29, no 1 (2001): 30, https://doi.org/10.1002/1520-6629(200101)29:1<29::aid-jcop3>3.0.co;2-c

2 Elisabeth J. Wood, "Field Research." In the Oxford handbook of comparative politics, edited by Carles Boix, Susan Carol Stokes. (Oxford: Oxford University Press, 2007), 125.

3 Diana Kapiszewski, Lauren M. MacLean, and Benjamin Lelan Read. Field research in political science. Practices and principles. Cambridge, United Kingdom, (2015), 109

4 Kapiszewski, MacLean and Read, Field research in political science, 1.

Kapiszewski, MacLean and Read, Field research in political science, 1.

Wood, Field Research, 123.
} 
fieldworks as "leaving one's home institution to acquire data, information, or insights that significantly inform one's research." ${ }^{\prime 7}$ However, the central component in both of the definitions, including the data collection approach adopted by this study is the interaction between the researcher and research participants. With such interactions likely to occur within sites that a researcher may be unfamiliar with, possible challenges as enumerated above are likely to surface.

This research note is not concerned with providing a step-by-step guide of field research. There are other works ${ }^{8}$ which offer a comprehensive insight into the strategies and the step-by-step approaches that researchers can adopt to design and prepare for field research. Instead, this paper relies on the fieldwork experiences gained by the authors during political science fieldwork to provide some practical suggestions on how one can manoeuvre some of the complexities that researchers would have to deal with when it comes to conducting fieldwork in a country such as Ghana. This note focuses on field researches in which the participants are ordinary citizens or residents within a particular community and not experts or respondents within a professional network. In the specific case of the study that informed the field experiences shared in this research note, the aim was to conduct surveys and in-depth interviews with eligible voters. The research was to help explore their experiences and the considerations that inform their decision to vote or not to vote, as well as the political and social context within the constituencies to ascertain how these contribute to the turnout decision-making. Hence, the experiences shared here may not necessarily benefit researchers whose target respondents are experts in the field, or members of a professional network but rather the ordinary citizens living within communities located within a rural and urban centre. The experiences and insights shared in this note should be of relevance to anyone considering conducting field research involving ordinary citizens in a developing-country context similar to Ghana.

The rest of this article is structured as follows: A brief contextualisation of the experiences shared in this note to provide insight into the research sites, types of research activities and nature of the research participants; and an overview of scenarios describing issues and complexities with the respective strategies to addressing them. From these, conclusions are drawn.

\section{Context}

The experiences discussed in this research notes were gathered from field research conducted in three constituencies in Ghana, namely Nanton, Assin North and Ellembelle, which are located in the Nothern, Central and Western regions of Ghana. A constituency is an electoral unit, demarcating the electoral boundaries for the election of people's representation to parliament. ${ }^{9}$ There are in all 275 constituencies in Ghana, out of which three were systematically selected to enable the collection of both quantitative and qualitative data to assess voter behaviour. The experiences shared cover two-rounds of extended field-stays covering a minimum of seven (7) days for each of the fields stays in each of the constituencies. Hence, the experiences being shared here cover in total six (6) field stays at eighteen (18) research sites producing 729 survey interviews, 52 in-depth interviews, 1 Focus Group Discussion (FGD) with market women, and participation in 2 pre-electoral community sensitisation events.

\section{Pre-Field Research Considerations Community Entry Strategy}

One of the keys and initial steps in identifying respondents for community research is to define the community entry strategies to be used. How can one get access to any community and to the relevant persons who could facilitate access to the respondents? This stage of any community research is deemed very critical to the outcome of a research project, as this lies at the base of eliciting the approval of community leaders as well as the cooperation of research participants. ${ }^{10}$ There are mostly leadership structures within any given community, and this within some African countries could be both traditional, i.e., a chief or regent ${ }^{11}$ and, or elected (appointed), local politicians. In Ghana, for instance, in addition to a chief, there is an assemblyman/woman. Similar positions to that of the assemblyman/woman is the ward councillor existing in countries like Nigeria and Zambia. ${ }^{12}$

Thus, in the case of Ghana, the contact person could be the assemblyman or woman, who is an elected local politician and representative of an electoral area. Since every community falls under an electoral area, there is an assemblyman or woman for every community in Ghana. These people are well informed about their communities. They are mostly educated and serve as an information transmission belt for their communities. Hence, they can easily

\footnotetext{
Kapiszewski, MacLean and Read, Field research in political science, 1

8 Carol Bailey, A guide to qualitative field research. 3rd ed, (Los Angeles: Sage Publications, 2018).

9 Raymond Baguio, Bening. "The Creation of Districts and Constituencies in Ghana: Some Pertinent Issues in the Current Dispensation," Ghana Journal of Geography 4 (2012) : 1-17

10 Shannon Smith et. al., Community entry in conducting rural focus groups: process, legitimacy, and lessons learned (The Journal of rural health: official journal of the American Rural Health Association and the National Rural Health Care Association, 2002).

11 The chief is the traditional leader who role a town or village. Nonetheless, in some case a regent and interim position, i.e. act in the capacity of a chief, awaiting for the installation of a new chief.

12 Assemblymen/women likewise councilors, are local politicians who are elected to represent their electoral areas at the local assembly level.
} 
understand research missions and would have probably engaged other research teams in the past, so it is not difficult to get their approval, and they can facilitate work within the community. They are also crucial to helping the research team get access to all the relevant actors and persons that would be needed for field research within the community. It is, therefore, crucial to first identify the electoral area within which the research site or the communities is located to help determine which assemblyman/woman to contact.

The question then is how one can get access to the assemblyman or woman? At least in the case of Ghana, the process can start from the District Assembly Office, where the contact of the assemblyman/ woman can be obtained. Another approach could be to go to the community and ask to see the assemblyman/ woman; they are usually wellknown, particularly in communities located within towns or villages. Upon establishing contact with the assemblyman/ woman and having introduced the research projects and the planned fieldwork to him/her, specific needs could be made known. This may include their suggestions on how to locate prospective respondents, possible NGOs or organisations working in and around the area, which could be of help, as well as a need for a liaison person who could assist the research team to locate respondents. Also important is the need for the research team or the leader of the research team to be introduced to the chief or regent of the community. At least in the case of Ghana, a meeting with the chief is important. Why is a visit to the chief's palace important? Any official activities that need to be engaged in within any community require approval or permission from the traditional leader of the village or town. Beyond that, getting approval from the chief sometimes helps with the process of building a good rapport with the locals. Once they know the traditional leader is aware and approves the exercise, people tend to be more welcoming. To highlight the importance of seeking approval from the chief, a real case as occurred in one of the constituencies where data was collected is briefly presented: In the first place, the assemblyman for the electoral area was met, and the project was introduced to him. In this particular case, there are four towns under this electoral area. He then assigned liaison persons for some of the communities since some members of the research team know the communities quite well and did not require help locating people. The assemblyman then arranged for a visit to the chief's palace for some of the communities. A visit to another chief's palace was overlooked, which resulted in the data collection exercise being halted at some point as some members of the communities got to know that the chief was not in the known of the exercise and was agitating. The situation got resolved with a visit to the palace before the exercise was continued. The above situation also draws attention to the need for the researcher to watch out for the bias or genuine oversights of the lead contact person as this could determine whom the researcher meets.

\section{Identification of Potential Respondents}

For a voter participation-related research, one source for data on possible respondents could be the voters' register. Though a request for a copy of the register could be made from the National Electoral Commission, it is better to address this request to the district office of the Electoral Commission. For a comparative research design of participants being eligible voters who voted and those who did not vote in a particular election year, the use of the voters' register would not enable the researcher to differentiate between voters and non-voters and the use of a random sampling technique might result in a dataset skewed towards voters. An alternative to the register in such cases would be the name reference list. This is the list that bears the names of all registered voters at each polling station, with the names of eligible voters who voted marked while those who did not vote unticked. Hence, this list offers the researcher the possibility to identify possible respondents and ascertain whether they voted or not. It is, however, worth noting that the access to -and use ofthis list should be guided by utmost discretion due to the ethical consideration of the secrecy of whether an individual vote or not

That said the need to use the name reference list would require critical considerations to a country's electoral law when developing the data collection plan. This is because specific electoral laws may guide access to such data. In Ghana, for instance, the electoral laws require that the election documents, including the marked copies of the register, should be sealed and forwarded to the Commission by the returning officer. ${ }^{13}$ These election-documents are kept for a year, after which they are destroyed unless otherwise directed by a court in respect to legal proceedings. Hence, access to the name reference list could prove challenging.

Experience from the field research on which this note is grounded, highlight the benefits of, and the possible access challenge to the name reference list. The name reference list was used, but only after the use of the voters' register produced a skewed dataset, primarily containing respondents who voted against those who did not vote. In two of the three constituencies, it was possible to access the name reference list, which facilitated the identification of potential respondents who did not participate in the 2016 election. Due to a post-election contestation of electoral results in the third constituency, access to the sealed election documents could not be granted. This lack of access to the reference list, therefore, necessitated the need to adopt a snowballing approach to identify people who did not vote in that year's

\footnotetext{
3 Electoral Commission Ghana, Public Election Regulation, 2016 (Accra: Electoral Commission of Ghana, 2016)
} 
election. The assemblymen were, however, instrumental in this regard, as to some extent, they knew some of the people who did not vote.

As earlier indicated, the assemblyman could assist the process of identifying respondents by assigning a local person to the research team. This person can be instrumental in helping the research team to locate either the homes or workplaces of respondents. Therefore, whether the source document being used is the voters' register or the name reference list, the assemblyman/woman could be helpful by assigning people who know the community very well and to a large extent they may know the people who did not vote. Another strategy, which could help in either the use of the register or the name reference list, is to recruit individuals who live within the community as research assistants. Individuals like teachers and recent tertiary institution graduates who are working with institutions located in, and around the communities are likely to have previous data collection experience and as such could with a day or two training workshops serve as field assistants. Valuable benefits enure to the projects when such individuals are used because they are very conversant with the community and know the people. They are most likely to speak the local language, hence can help to easily administer questionnaires or conduct interviews with locals who only speak the local language.

\section{On-Site Scenarios and Possible Challenges}

Beyond the initial challenges of community entry, other field-related challenges may occur. This may include the nonavailability of potential respondents, and if the research involves sensitive topics, then one could be faced with the unwillingness of some respondents to be interviewed and or to be recorded. One could even face a situation where some respondents would not want to divulge information. These issues are briefly discussed below.

\section{Non-availability of potential respondents}

One of the likely challenges that researchers can face in field research is the non-availability of potential respondents. Research design with voters or non-voters as research participants are likely to meet the absence of potential respondents. This is particularly eminent in communities known for seasonal or rural-urban migration with the youths travelling out of their communities to urban centres in search of jobs. Thus for a research design focused on voter participation, these people could be momentarily unavailable since though they are registered and vote in the constituencies, they may not be around after the election. Equally, the challenge of non-availability of respondents could occur when the data collection is done during working hours when people have gone to work, farm, or to the market. What this implies is that though one could quickly identify potential respondents using the voter's register or even the name reference list, it is also possible that potential voters are not readily available because they have travelled or gone to work. What can be done in such situations?

A necessary item to prepare is a supplementary list of potential replacers to augment the main list of potential respondents. This is particularly relevant to address the situation where potential respondents are not available due to travels. For non-availability, due to participants having gone to work, in addition to replacing such respondents or scheduling the data collection to evenings or weekends, especially Sundays, the research team could visit the workplace of potential respondents. The possibility of administering a questionnaire or conducting an in-depth interview with a participant at their place of work is feasible mainly because most people within an African country context are employed within the informal sector. ${ }^{14}$ In Ghana, for instance, as high as $88.8 \%$ of the population is engaged in the informal sector. ${ }^{15}$ What this means is that people may either be self-employed or working in an environment which could make it possible for them to grant research interviews or to participate in a survey.

\section{Unwillingness to have Interviews Recorded}

Another challenge likely to be faced in the field is the reluctance on the part of some research participants to have interviews recorded. This is particularly likely to occur when the research subject matter is sensitive. A case in point occurred during the field research being referenced in this paper. Due to the proximity of the general election to the data collection exercise, potential participants misconstrued the research agenda as being commissioned by the incumbent party that had just lost the election to ascertain the reasons for its loss. Not only could the reluctance of a potential research participant to be recorded be born out of misconceptions but also genuine concerns over the confidentiality of the information they would give out, as well as of their identity. Hence, even when the participant does not openly register concerns over the recording of the interview, they may engage in some self-auditing to ensure that they sound socially desirable. That is the "tendency of some respondents to report an answer in a way they deem to be more socially

\footnotetext{
14 Arvil V., Adams, Sara Johansson de Silva, and Setareh Razmara. Improving skills development in the informal sector (Strategies for Sub-Saharan Africa. (Washington, D.C.: The World Bank, 2013), 1.

15 "Statistics on the informal economy", International Labour Organization, 2015, accessed October 15, 2020, https://ilostat.ilo.org/topics/informality/.
} 
acceptable than would be their true answer" ${ }^{16}$

A case in point occurred during an interview in one of the constituencies of the reference research used in this paper. In an interview with a community leader, it was realised that the responses being given was being 'massaged,' ${ }^{17}$ of which further probing by the researcher did not change the participant's disposition. Sometime later, during the interview, the participant stated the following "madam, put off the recorder". It was only then that the participant started divulging information, which hitherto he was reluctant to do. What this implies is that even when a researcher follows the standard procedure of seeking permission to record, and the participant agrees, there is still the possibility that the participant would engage in self-auditing and as such, there is the need for the researcher to watch out for that. A researcher cannot achieve the aptness to decipher when this is occurring, only by gaining knowledge of the research topic but also knowing the research site and the local socio-political dynamics of that area. To do this, information obtained through earlier interviews and interactions within the research community could be helpful.

In cases where the potential research participant is unwilling, the researcher could consider the following: Aside from the assurance of confidentiality and anonymity, ${ }^{18}$ a detailed explanation should be given as to why the interview had to be recorded, i.e. for instance to facilitate documentation as well as ensure the flow of the interview. Also, other solutions could be proposed, which may include a replay of the entire interview for the interviewee to indicate parts of the recording that they would wish to be taken out. Alternatively, the researcher should indicate to the interviewee that if in the course of the interview, questions are asked, and they are uncomfortable, they are at will to decline to respond. A third solution could be to offer to share a copy of the recording with the interviewee, either a transcribed or an audio version. This could be especially helpful in cases where the respondent is concerned that what they say would be misconstrued or altered. A final suggestion would be that as has been recommended by some, ${ }^{19}$ "not recording is the best approach, not second best": A statement, which is found to be right in the field experience, shared above.

\section{Dealing with the dilemma of -and the expectation for Incentive}

One of the dilemmas that researchers have to sometimes deal with is the issue of compensating study participants for their time. The compensation of research participants has been deemed as nothing out of the ordinary and as such, has received attention in research in terms of the ethical implication as well as its impact on research. ${ }^{20}$ Its use as has been argued by some ${ }^{21}$ helps in increasing response rates. Others have also argued that offering monetary compensation can induce participants, particularly those who are vulnerable. ${ }^{22}$ Offering financial compensation to research participants has also been contended to impact on the principle that information obtained in research is supposed to be a freely given consent, ${ }^{23}$ thus compensating participants could potentially influence the kind of information that is given out or even result in creating a culture of expectation for participation in future research. ${ }^{24}$

That said, Kapiszewski et al. have also noted that the normative expectations for immediate financial or in-kind compensation may vary based on field settings. ${ }^{25} \mathrm{In}$ a developed country context, monetary incentives are usually given to study participants. ${ }^{26}$ In an African country context, some reasons could inform expectations for such incentives. This may include experiences from past fieldworks where payments were made, ${ }^{27}$ which by the way is not limited to the African context since, in an experiment, Head, for instance, found that the expectation by potential research participants of being compensated was grounded on the fact that cash payment was made in previous fieldwork. ${ }^{28}$ As was found in the reference field research used in this, participants could develop such expectations out of the fact that they have not

\footnotetext{
16 Mario, Callegaro, "Social Desirability," in Encyclopedia of Survey Research Methods and ed. Paul Lavrakas, (London: Sage Publications, 2008 ), 825.

17 The term massage is used to denote the situation where a research participant tries to manipulate the information that is given out, particularly when the information is perceived to be sensitive.

18 Floyd J., Fowler, Survey research methods, rev. ed. (Los Angeles: SAGE Applied social research methods series, 2014), 95

19 Rwamahe, Rutakumwa, Joseph O. Mugisha, Sara Bernays, Elizabeth Kabunga, Grace Tumwekwase, Martin Mbonye, and Janet Seeley. "Conducting in-depth interviews with and without voice recorders: a comparative analysis." Qualitative Research 20, no 5 (2020): 565. http://dx.doi.org/10.1177/1468794119884806.

20 Emma, Head. “The ethics and implications of paying participants in qualitative research.” International Journal of Social Research Methodology 12, no 4 (2009): 335, http://dx.doi.org/10.1080/13645570802246724.

21 Phil, Edwards, Ian Roberts, Mike Clarke, Carolyn DiGuiseppi, Sarah Pratap, Reinhard Wentz, and Irene, Kwan. "Increasing response rates to postal questionnaires: systematic review." BMJ: Bristich Medical Journal, vol. 324, no. 7347 (2002): 108, http://dx.doi.org/10.1136/bmj.324.7347.1183. Eleanor, Singer and Richard Kulka, Paying Respondents for Survey Participation.” In Studies of Welfare Populations: Data Collection and Research Issues, and ed. Michele ver Ploeg, Robert A. Moffitt, and Constance F. Citro (Washington D.C.: National Academy Press, 2002) 107. Mario, Teisl. F., Brian Roe, and Michael Vayda. "Incentive Effects on Response Rates, Data Quality, and Survey Administration Costs." International Journal of Public Opinion Research 18, no 3(2006): 364, http://dx.doi.org/10.1093/ijpor/edh106.

22 Emily, Paradis, K. "Feminist and community psychology ethics in research with homeless women." American journal of community psychology 28, no 6 (2000): 846, http://dx.doi.org/10.1023/a: 1005115901078.

23 Head. "The ethics and implications of paying participants in qualitative research," 342.

24 Neil, McKeganey. “To pay or not to pay: respondents' motivation for participating in research.” Addiction (Abingdon, England) 96 no 9 (2001): 1237 , http://dx.doi.org/10.1046/j.1360-0443.2001.96912371.x.

25 Kapiszewski, MacLean and Read, Field research in political science 325

26 McKeganey. "To pay or not to pay 148.

27 McKeganey. "To pay or not to pay 148.

28 Head. "The ethics and implications of paying participants in qualitative research." 343.
} 
seen benefits accruing to the community from their participation in past research projects. In some of the communities visited in the referenced field research used in this paper, some of the potential participants did complain about the fact that participation in past research projects did not yield any benefits for the community. Hence, they are reluctant to participate in yet another research project, particularly when no incentive would be given to them for the use of their time and effort.

Dealing with such a dilemma requires taking the local context into perspective. Recommendations on how to handle such dilemmas or even how much or what to give could also be sought from local experts. ${ }^{29}$ For research projects with substantial research funds, such expectations could be met. ${ }^{30}$ Nonetheless, for low-budget research such as those by most graduate students, the researcher must find a way to indicate comprehensively what it means, that is, the project serves abstract academic purposes. Alternatively, in-expensive souvenirs could be offered and should not be considered unethical, but rather appreciative.

\section{CONCLUSIONS}

The above discussion has shed light into some before and on-field issues that researchers need to give considerations to particularly for novice researchers or those with research designs that require fieldworks. This note complements earlier literature, which provides step-by-step guides to field research. This paper is a guide for field research in an African country context. It provides experienced-based suggestion on how to deal with entering into a research community, identifying and contacting potential respondents, the non-availability of respondents, the unwillingness of participants to be recorded, as well as, the dilemma and expectations of compensating research participants. The suggestions are particularly relevant for research designs involving communities of so-called ordinary people whereas interviewing professionals may need to follow different strategies.

\section{ABOUT AUTHORS}

Fortune Agbele, MPP, PhD Candidate and Junior Fellow, Bayreuth International Graduate School of African Studies (BIGSAS), University of Bayreuth, Germany.

Dr Alexander Stroh, Junior Professor of Political Science, Faculty of Humanities and Social Sciences, and Senior Fellow of the Bayreuth International Graduate School of African Studies (BIGSAS), University of Bayreuth, Germany.

\section{BIBLIOGRAPHY}

Adams, Arvil V., Sara Johansson de Silva, and Setareh Razmara. Improving skills development in the informal sector. Strategies for Sub-Saharan Africa. Washington, D.C.: The World Bank, 2013.

https://doi.org/10.1596/9780821399682_ch02

Bailey, Carol. A guide to qualitative field research. 3rd ed, Los Angeles: Sage Publications, 2018.

Bening, Raymond Baguio. "The Creation of Districts and Constituencies in Ghana: Some Pertinent Issues in the Current Dispensation." Ghana Journal of Geography, no 4 (2012): 1-17.

Callegaro, Mario. Social Desirability. In Encyclopedia of Survey Research Methods. Edited by Paul Lavrakas, 825-826. London: Sage Publications, 2008.

Edwards, Phil, Ian Roberts, Mike Clarke, Carolyn DiGuiseppi, Sarah Pratap, Reinhard Wentz, and Irene, Kwan. "Increasing response rates to postal questionnaires: systematic review." BMJ: British Medical Journal, 324, no 7347 (2002): 1183. https://doi.org/10.1136/bmj.324.7347.1183

Electoral Commission of Ghana. Public Election Regulation, 2016. Accra: Electoral Commission of Ghana, 2016.

Fowler, Floyd J. Survey research methods. 5th ed. Los Angeles: SAGE Applied social research methods series, 1, 2014.

Head, Emma. "The ethics and implications of paying participants in qualitative research." International Journal of Social Research Methodology 12, no 4 (2009): 335-344. https://doi.org/10.1080/13645570802246724

Kapiszewski, Diana, Lauren M. MacLean, and Benjamin Lelan Read. Field research in political science.Practices and Principles. Cambridge, United Kingdom, 2015. https://doi.org/10.1017/cbo9780511794551

Lupu, Noam and Kristin Michelitch. "Advances in Survey Methods for the Developing World." Annual. Review of Political Science. 21, no 1 (2018): 195-214. https://doi.org/10.1146/annurev-polisci-052115-021432

\footnotetext{
29 Noam, Lupu and Kristin Michelitch, “Advances in Survey Methods for the Developing World.” (Annual. Review of Political Science. 21, no 1 (2018): 205, http://dx.doi.org.10.1146/annurev-polisci-052115-021432 2018).

30 Kapiszewski, MacLean and Read, Field research in political science, 148
} 
McKeganey, Neil. “To pay or not to pay: respondents' motivation for participating in research.” Addiction (Abingdon, England) 96 no 9 (2001): 1237-1238. https://doi.org/10.1046/j.1360-0443.2001.96912371.x

Paradis, Emily. K. "Feminist and community psychology ethics in research with homeless women." American Journal of Community Psychology 28, no 6 (2000): 839-858. https://doi.org/10.1023/a:1005115901078

Prezza, Miretta, Matilde Amici, Tiziana Roberti, and Gloria Tedeschi. "Sense of Community Referred to the Whole Town: Its Relations with Neighboring, Loneliness, Life Satisfaction, and Area of Residence." Journal of Community Psychology 29, no 1 (2001): 29-52. https://doi.org/10.1002/1520-6629(200101)29:1<29::aid-jcop3>3.0.co;2-c

Rutakumwa, Rwamahe, Joseph O. Mugisha, Sara Bernays, Elizabeth Kabunga, Grace Tumwekwase, Martin Mbonye, and Seeley Janet. "Conducting in-depth interviews with and without voice recorders: a comparative analysis." Qualitative Research 20, no 5 (2020): 565-581. https://doi.org/10.1177/1468794119884806

Singer, Eleanor and Richard Kulka. "Paying Respondents for Survey Participation.” In Studies of Welfare Populations: Data Collection and Research Issues, edited by Michele ver Ploeg, Robert A. Moffitt, and Constance F. Citro, 105-128. Washington, D.C.: National Academy Press, 2002.

Smith, Shannon L., Kelly Blake, Carol R. Olsen, and Irene Tessaro. "Community entry in conducting rural focus groups: process, legitimacy, and lessons learned." The Journal of Rural Health: Official Journal of the American Rural Health Association and the National Rural Health Care Association 18, no 1 (2002):118-123. https://doi.org/10.1111/j.1748-0361.2002.tb00883.x

"Statistics on the informal economy", International Labour Organization, 2015. Accessed October 15, 2020, https://ilostat.ilo.org/topics/informality/.

Teisl, Mario. F., Brian Roe, and Michael Vayda. "Incentive Effects on Response Rates, Data Quality, and Survey Administration Costs." International Journal of Public Opinion Research 18, no 3(2006): 364-373. https://doi.org/10.1093/ijpor/edh106

Wood, J. Elisabeth. "Field Research." In the Oxford handbook of comparative politics, edited by Carles Boix, Susan Carol Stokes, 123-146. Oxford: Oxford University Press, 2007. https://doi.org/10.1093/oxfordhb/9780199566020.003.0005 